\title{
Fabrication and Characterization of Composite LSCF-Ag Cathode for Solid Oxide Fuel Cells using Electron Beam Irradiation Process
}

\author{
Hyun Suk Kang, ${ }^{\dagger,}$ Yung-Min Jung, ${ }^{\ddagger}$ Rak-Hyun Song, ${ }^{\ddagger}$ Dong-Hyun Peck, ${ }^{\ddagger}$ ChangMoon Park, ${ }^{\S}$ and Byung Cheol Lee ${ }^{\dagger, *}$ \\ ${ }^{\dagger}$ Radiation Integrated System Research Division, Korea Atomic Energy Research Institute (KAERI), Yuseong, \\ Daejeon 305-353, Korea. *E-mail: bclee4@kaeri.re.kr \\ $\$$ Fuel Cell Research Center, Korea Institute of Energy Research (KIER), Yuseong, Daejeon 305-343, Korea \\ ${ }^{\S}$ Department of Chemistry, Chungnam National University, Yuseong, Daejeon 305-764, Korea \\ Received February 12, 2014, Accepted June 13, 2014
}

\begin{abstract}
A new process to fabricate a composite LSCF-Ag cathode material for SOFCs by electron beam (e-beam) irradiation process has been suggested for operation under intermediate temperature range of $600-700{ }^{\circ} \mathrm{C}$. A composite LSCF-Ag cathode with uniformly coated Ag nanoparticles on the surface of the LSCF material was prepared by a facile e-beam irradiation method at room temperature. The morphology of the composite LSCFAg material was analyzed using a TEM, FE-SEM, and EDS. The prepared composite LSCF-Ag material can play a significant role in increasing the electro-catalytic activities and reducing the operating temperature of SOFCs. The performance of a tubular single cell prepared using the composite LSCF-Ag cathode, YSZ electrolyte and a Ni/YSZ anode was evaluated at reduced operating temperature of $600-700{ }^{\circ} \mathrm{C}$. The microstructure and chemical composition of the single cell were investigated using a FE-SEM and EDS.
\end{abstract}

Key Words : Electron beam irradiation, LSCF-Ag cathode, Solid oxide fuel cell

\section{Introduction}

Fuel cells offer high conversion efficiencies and a modular power generation system, because they generate electrical energy directly from chemical energy and can be assembled as a modular fuel cell stack. Among the many types of fuel cells, solid oxide fuel cells (SOFCs) are an attractive electric power and thermal generation system with energy conversion efficiency as high as $80 \%$ for electricity and thermal energy.

Whereas SOFCs have higher efficiency than other types of fuel cells, they have several weaknesses including interdiffusion of cell materials and sealing problems at high operating temperatures of $850-900{ }^{\circ} \mathrm{C}$. To resolve those problems, many research groups have attempted to lower the operating temperature of the cells to an intermediate temperature range of $600-700^{\circ} \mathrm{C}$ and to develop new cell materials.

The performance of a SOFC is controlled significantly by the oxygen reduction reaction (ORR) in the cathode. To obtain high performance at the cathode, developing high activity cathode materials and optimizing the microstructure of the cathode is necessary. Developing new cathode materials is very important to improve the performance of SOFCs. Conductive perovskite oxides, such as $\mathrm{La}_{1-\mathrm{x}} \mathrm{Sr}_{\mathrm{x}} \mathrm{MnO}_{3}$ (LSM), $\mathrm{La}_{1-\mathrm{x}} \mathrm{Sr}_{\mathrm{x}} \mathrm{CoO}_{3}$ (LSC), $\mathrm{La}_{1-\mathrm{x}} \mathrm{Sr}_{\mathrm{x}} \mathrm{FeO}_{3}$ (LSF), and $\mathrm{La}_{1-\mathrm{x}} \mathrm{Sr}_{\mathrm{x}} \mathrm{Co}_{1-\mathrm{y}}{ }^{-}$ $\mathrm{Fe}_{\mathrm{y}} \mathrm{O}_{3}$ (LSCF) mixed with noble metals, including palladium, platinum, and silver (typically $<5 \mathrm{wt} \%$ ), have been the subject of numerous SOFC-related studies due to their increased activity towards oxygen reduction. ${ }^{1-8}$

Perovskite oxides with the composition of a LSCF material are mixed ionic and electronic conductors (MIECs). LSCF is one of the most promising cathode materials for SOFCs based on its high ionic and electronic conductivities, high electro-catalytic activities, good chemical stability, and fast oxygen surface exchange rate. ${ }^{9,10}$ LSCF presents high catalytic activity in the ORR and conducts ionic current both at the surface and in the bulk. However, below $700{ }^{\circ} \mathrm{C}$, the ionic conductivity of LSCF rapidly decreases. To address this, new cathode materials such as composite LSCF-Ag materials have been suggested for high performance cathode materials under intermediate temperatures of $600-750{ }^{\circ} \mathrm{C} .{ }^{11}$ Silver (Ag) has been studied as a candidate electrode material in this temperature range because of its high electronic conductivity, electro-catalytical activity for the ORR and substantial oxygen solubility and mobility. ${ }^{12,13}$

The electron beam (e-beam) irradiation process a generally high reaction rate and is a very simple process for the preparation of homogenous nano-particles..$^{9,10}$ Moreover, this process results in fewer by-products and is a continuous manufacturing process. It thus has strong prospects for mass production of nano-particles based cathode. In the e-beam irradiation process, the reduced power of radicals that are decomposed by e-beam irradiation is exploited.

The electron beam irradiation method has advantages over other techniques such as short reaction time, simple operation, utility for mass production, and the absence of chemical residues after the reaction. ${ }^{14,15}$

$$
\begin{aligned}
& \mathrm{G}(\cdot \mathrm{OH})=\mathrm{G}(\text { eaq- })=\mathrm{G}\left(\mathrm{H}_{3} \mathrm{O}^{+}\right)=0.28, \mathrm{G}(\cdot \mathrm{H})=0.062 \text { and } \\
& \mathrm{G}\left(\mathrm{H}_{2}\right)=0.042, \mathrm{G}\left(\mathrm{H}_{2} \mathrm{O}_{2}\right)=0.082
\end{aligned}
$$

The G-value is the number of molecules of product formed, or of starting material changed, for every $100 \mathrm{eV}$ of energy absorbed. ${ }^{16}$ Mostly, these radicals have a short span on the scale of nano- or micro- seconds and high activity 
gives rise to reaction of ions with other ions. The metal precursor is dissolved in water as ions, and they are reduced in the form of metal after they meet hydrated electrons in water. These reduced metals agglomerate to form nano- and micro- particles of metals.

In this study, a new preparation process for a composite LSCF-Ag cathode material was developed using the easy and simple e-beam irradiation process carried out at room temperature. A composite LSCF-Ag cathode with uniformly coated Ag nanoparticles on the surface of LSCF cathode materials was prepared by the e-beam irradiation method. The morphology of the composite LSCF-Ag material was analyzed using a TEM, FE-SEM, and EDS. The performance of a tubular single cell prepared using the composite LSCF-Ag cathode, ScSZ electrolyte, and a Ni/ScSZ anode was evaluated at reduced operating temperature of 600-700 ${ }^{\circ} \mathrm{C}$. The microstructure and chemical composition of the single cell were investigated using a scanning electron microscope (FE-SEM) equipped with an energy dispersive $\mathrm{X}$-ray analyzer (EDS).

\section{Experimental}

Silver nitrate $\left(\mathrm{AgNO}_{3}\right.$, Junsei, 99.9\%, Japan) was used as the precursor of nano Ag powder without any further purification. Polyvinyl alcohol (PVA, Sigma-Aldrich, $\mathrm{Mw}=$ 2000) was used as a dispersing agent. Isopropyl alcohol (IPA, 99\%, Duksan Co., Korea) was used as a radical scavenger and sulfuric acid $\left(\mathrm{H}_{2} \mathrm{SO}_{4}\right.$, Sigma-Aldrich, 95\%) as a surface modification agent. A commercial LSCF ( $\mathrm{La}_{0.6}-$ $\mathrm{Sr}_{0.4} \mathrm{Co}_{0.2} \mathrm{Fe}_{0.8} \mathrm{O}_{3-\delta}$ ) powder (Kceracell Co., Korea) was used without further purification as a cathode component and the BET of this LSCF powder was $10-15 \mathrm{~m}^{2} / \mathrm{g}$.

Figure 1 shows the preparation schema for Ag nanoparticle coated-LSCF by the e-beam irradiation process. To modify the LSCF powders, the as-received LSCF powder was dispersed in a sulfuric acid solution that was diluted 50fold in distilled water and was mixed for $30 \mathrm{~min}$ using a stirrer at room temperature. The treated LSCF powders were rinsed in a filtering system with distilled water several times to remove the sulfuric acid in the powders.

The treated LSCF powders were mixed with the Ag precursor, composed of $10 \mathrm{wt} \%$ of silver nitrate and PVA (10 ppm), and stirred for $30 \mathrm{~min}$. IPA (5 wt \%) as a radical scavenger was then added into the mixed solution of treated LSCF powders and Ag precursors to yield a more active reducing reaction by removing the oxidizing radicals. The mixture was further stirred for $10 \mathrm{~min}(200 \mathrm{rpm})$ and

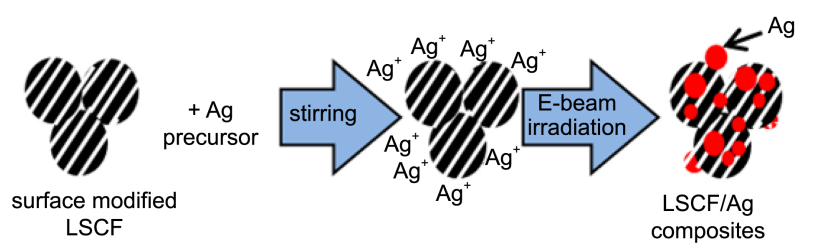

Figure 1. Preparation schema for Ag nanoparticles coated LSCF by e-beam irradiation process. irradiated by an e-beam for preparation of LSCF-Ag composite powders. The irradiation conditions of the e-beam equipment (Korea Atomic Energy Research Institute, Korea) are $1 \mathrm{MeV}, 5 \mathrm{~mA}$, and $300 \mathrm{kGy}$ at room temperature. Finally, the prepared composite LSCF-Ag powder was obtained after drying at $80{ }^{\circ} \mathrm{C}$ for $12 \mathrm{~h}$. LSCF-Ag powders containing 10 wt \% Ag were thus obtained by the e-beam irradiation process conducted at room temperature. The morphology and particle size of the composite LSCF-Ag powder was characterized using a TEM (FEI Company, Tecnai G2 F30 (300 kV), USA) and FE-SEM (Hitach, S-4800, Japan).

The anode-supported tube is a fuel electrode (Ni/YSZ). An anode functional layer (ScSZ-Ni), a gadolinia doped ceria (GDC) buffer layer, and an electrolyte layer (ScSZ) were coated onto the anode support by a slurry dip-coating method, respectively. The coated ScSZ electrolyte and GDC buffer layers were co-fired at $1400{ }^{\circ} \mathrm{C}$ for $5 \mathrm{~h}$. The gadolinia doped ceria (GDC) was used as an interlayer to prevent inter-reaction between the ScSZ electrolyte and the LSCF$\mathrm{Ag}$ cathode. The chemical compositions of the YSZ, ScSZ, and GDC materials were $\left(\mathrm{Y}_{2} \mathrm{O}_{3}\right)_{0.08}\left(\mathrm{ZrO}_{2}\right)_{0.92},\left(\mathrm{Sc}_{2} \mathrm{O}_{3}\right)_{0.1^{-}}$ $\left(\mathrm{CeO}_{2}\right)_{0.01}\left(\mathrm{ZrO}_{2}\right)_{0.89}$, and $\mathrm{Gd}_{0.10} \mathrm{Ce}_{0.90} \mathrm{O}_{1.95}$, respectively. The cathode layer was coated with the composite LSCF-Ag material onto the electrolyte layer by a dip-coating method and sintered at $850{ }^{\circ} \mathrm{C}$ for $3 \mathrm{~h}$ in air. ${ }^{17}$ The sintering temperature of the composite LSCF-Ag cathode prepared by the e-beam irradiation process can be reduced to $850{ }^{\circ} \mathrm{C}$ because the Ag particles are very small (about $10 \mathrm{~nm}$ ) and have high sintering activity. The active electrode area of the tubular single cell was $4.5 \mathrm{~cm}^{2}$ (L: $1 \mathrm{~cm}$, O.D.: $0.1 \mathrm{~cm}$, I.D.: $0.8 \mathrm{~cm}$ ). The cell performance of the tubular single cell with the composite LSCF-Ag cathode was measured at $600-700{ }^{\circ} \mathrm{C}$ while supplying humidified $\mathrm{H}_{2}(0.15 \mathrm{slm})$ with $3 \mathrm{wt} \% \mathrm{H}_{2} \mathrm{O}$ and air $(1.2 \mathrm{slm})$.

The fractured microstructure and chemical composition of the single cell were also investigated using a FE-SEM (Hitachi, S-4800, Japan) equipped with an EDS.

\section{Results and Discussion}

Figures 2(a) and (b) show SEM images of the LSCF powder before and after modification with sulfuric acid solution, respectively. The as-received LSCF powder before the modification process (a) shows a heavily agglomerated morphology and the modified powder (b) shows a well dispersed and fine particle morphology. The modified LSCF powder clearly shows a more homogenous distribution of particles than the LSCF powder before modification. The mean particle size of the modified LSCF powder was 0.3 $\mu \mathrm{m}$.

The chemical composition of LSCF, examined by EDX (Energy-dispersed X-ray analysis) was not changed before and after modification with sulfuric acid solution of 0.01 Mol.

The particle morphology of the LSCF-Ag composite powder with Ag coated on the modified LSCF powder after the e-beam irradiation process was analyzed by SEM (Figs. 

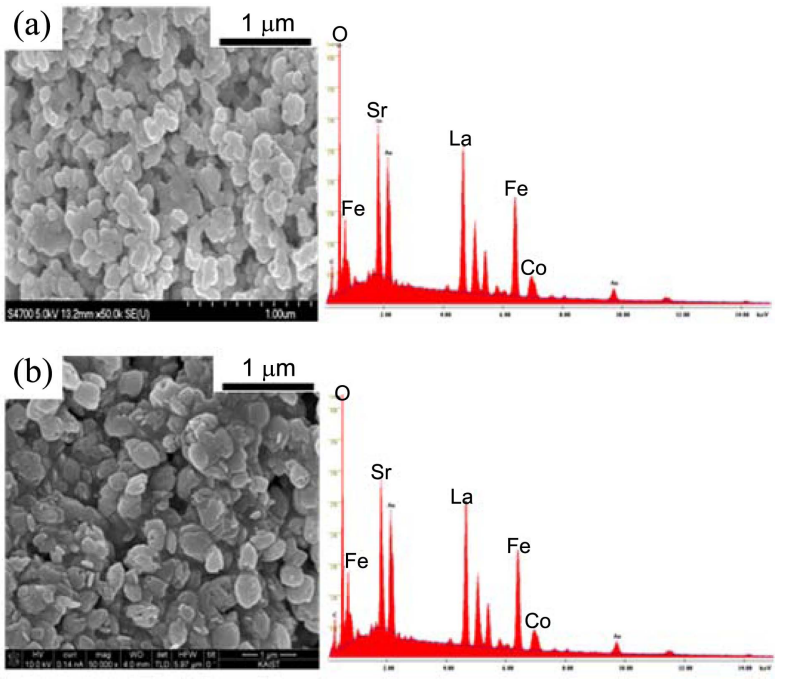

Figure 2. SEM images of LSCF powders (a) before and (b) after modification with sulfuric acid solution.
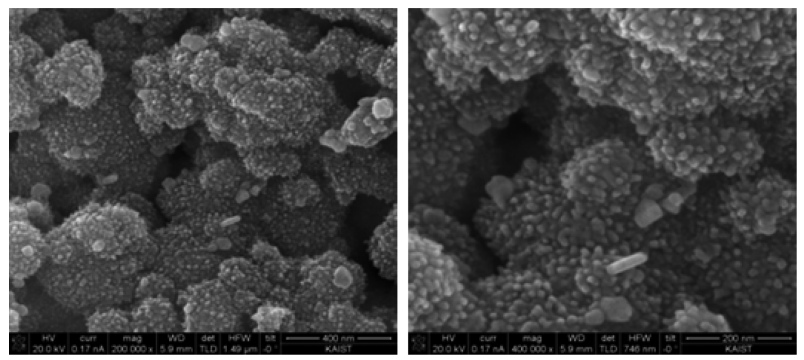

Figure 3. SEM images of LSCF-Ag composite.

3(a) and (b)). As shown in Figures 3(a) and (b), Ag nanoparticles are well coated and uniformly distributed on the surface of the LSCF powders.

The particle sizes of the modified LSCF powder and Ag nano-particles are about $0.2-0.4 \mu \mathrm{m}$ and $10 \mathrm{~nm}$, respectively. The LSCF-Ag composite powder was also analyzed by TEM (Figs. 4(a) and (b)). As shown in Figure 4, the Ag nano-particles are round and homogeneous with size of 10 $\mathrm{nm}$ and are uniformly distributed on the LSCF powders. The
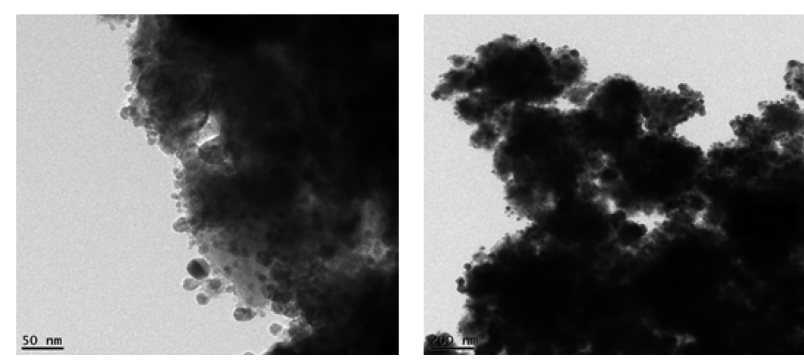

Figure 4. TEM images of LSCF-Ag composite.

particle sizes of the Ag and LSCF particles are consistent with the results of the TEM analysis.

To further understand the morphology, chemical composition, and element distribution of $\mathrm{La}, \mathrm{Sr}, \mathrm{Co}, \mathrm{Fe}$, and $\mathrm{Ag}$ in the composite LSCF-Ag material, TEM and X-ray mapping image analyses using a TEM system were performed (Fig. 5).

The results (Fig. 5) revealed that Ag particles of roughly $10 \mathrm{~nm}$ diameter are distributed homogeneously in the composite LSCF-Ag powder. The X-ray mapping image and $\mathrm{Ag}-\mathrm{K} \alpha$ spectrum confirm that nano-sized and uniformed $\mathrm{Ag}$ particles were well coated on the LSCF powder. The elemental distribution of fine silver particles is relatively uniform in the LSCF-Ag powder..$^{10}$ The elements $\mathrm{La}, \mathrm{Sr}, \mathrm{Co}$, and $\mathrm{Fe}$ are also homogeneously distributed in the composite LSCF-Ag materials. ${ }^{14}$ It was reported that the LSM-Ag composite powder has a fine structure with a homogeneous distribution of Ag and LSM, which effectively shortens the diffusion pathways for electrons and adsorbed oxygen. The results reported that the LSM-Ag composite powder has a fine structure with a homogeneous distribution of $\mathrm{Ag}$ and LSM, which effectively shortens the diffusion pathways for electrons and adsorbed oxygen.

Figure 6(a) shows a SEM image of a cross-section of a single cell composed of a LSCF-Ag cathode, a GDC interlayer, $10 \mathrm{ScSZ}$ electrolyte, and a Ni/ScSZ anode support tube. The cell was fabricated with a dense electrolyte and porous cathode and anode, with a GDC interlayer applied between the electrolyte and the cathode layers. The thickness of the ScSZ electrolyte, GDC interlayer, and composite
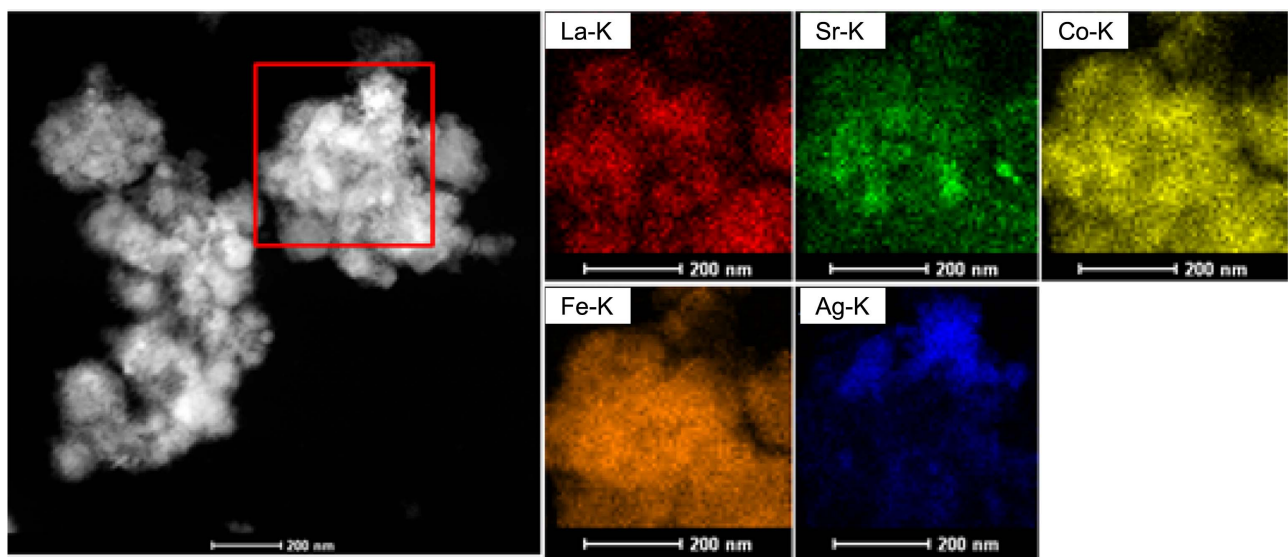

Figure 5. X-ray mapping images of LSCF-Ag composite. 


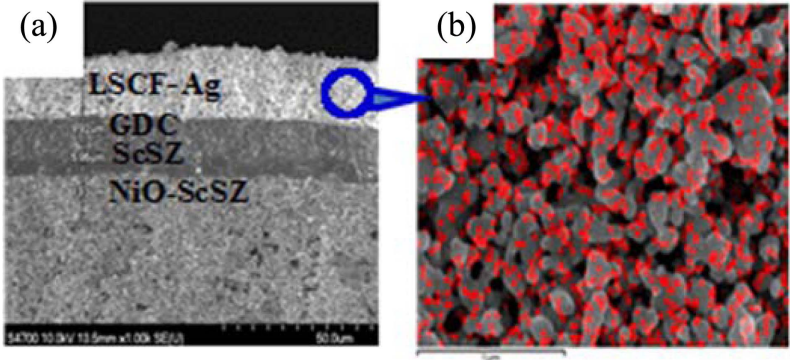

Figure 6. (a) SEM image of a cross-section of a single cell and (b) X-ray mapping image of the fractured surface of the composite LSCF-Ag cathode in a single cell. Silver is indicated by the red points.

LSCF-Ag cathode was approximately 5.95, 9.92, and 16.5 $\mu \mathrm{m}$, respectively. As shown in Figure 6(a), the GDC functional layer prevent the inter-reactions between ScSZ electrolyte and LSCF cathode layer. The thickness of GDC layer should have sufficient thickness to prevent the inter-diffusion or interpenetration of LSCF particles in GDC layer. The optimum thickness of DGC layer should investigate in other detail works, because the thickness of $9.92 \mu \mathrm{m}$ is not a best fitted conditions.

To show the distribution of Ag nanoparticles on the surface of LSCF, the microstructure of the composite LSCF-Ag cathode in the single cell was analyzed using an EDS in a SEM system. Figure 6(b) shows an X-ray mapping image of the $\mathrm{Ag}$ element (indicated by red points) of the fractured surface of the composite LSCF-Ag cathode in a single cell. $\mathrm{Ag}$ accumulated on the LSCF-Ag cathode, as shown in the X-ray mapping image (Fig. 6(b)).

The fine silver particles are distributed over the porous LSCF electrode. This is evidence of a uniform distribution of Ag nano-particle on the surface of LSCF particles in the cathode without any aggregation and volatilization of $\mathrm{Ag}$ nano-particles in the single cell. ${ }^{12} \mathrm{Ag}$ powder in the electrode can improve the electrochemical performance and is an electro-catalytically active element. ${ }^{13}$ The LSCF in the LSCF-

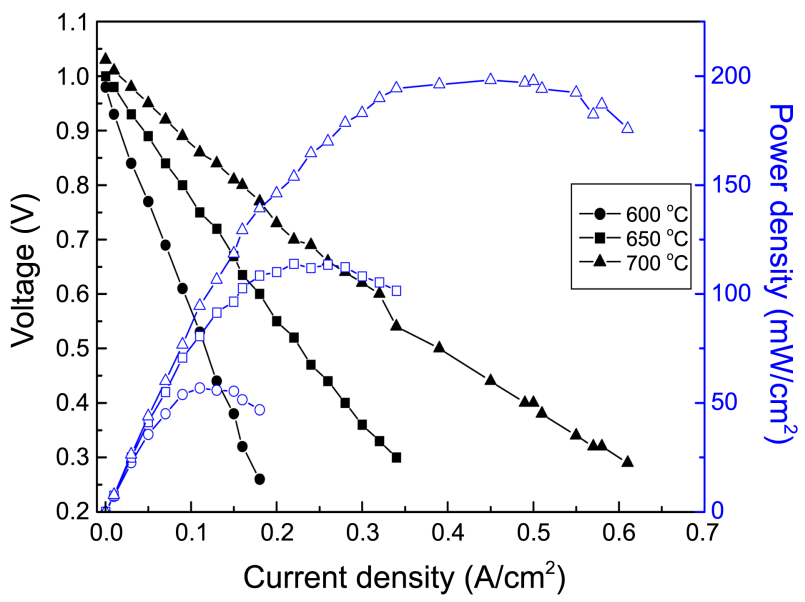

Figure 7. Performance of a single tubular cell prepared using a composite LSCF-Ag cathode.
Ag composite may serve as a barrier to large scale Ag agglomeration, thereby maintaining its effectiveness. ${ }^{18}$ The sintering temperature of the composite LSCF-Ag cathode prepared by the e-beam irradiation process could be reduced to $850{ }^{\circ} \mathrm{C}$ for $3 \mathrm{~h}$. The reduction of the sintering temperature could be explained by the small particle size $(10 \mathrm{~nm})$ and high sintering activity of the fine Ag particles over the LSCF matrix. The fine Ag particles were homogenously distributed over the LSCF matrix.

Figure 7 shows the current/voltage (I/V) and current/ power (I/P) curves of a tubular single cell composed of a composite LSCF-Ag cathode, a GDC interlayer, ScSZ electrolyte and a Ni/ScSZ anode support tube at 600, 650, and $700{ }^{\circ} \mathrm{C}$, respectively. As seen in the figure, the maximum power densities were $56.9,113.9$, and $198.1 \mathrm{~mW} / \mathrm{cm}^{2}$ where the operation temperatures of the single cell were 600,650 , and $700{ }^{\circ} \mathrm{C}$, respectively.

\section{Conclusion}

A new fabrication process for a composite LSCF-Ag cathode using e-beam irradiation for application to SOFCs to reduce the operating temperature was developed. The asreceived LSCF powder was modified by sulfuric acid diluted 50 -fold in distilled water to increase the specific surface area of the materials. The e-beam irradiation technique was used to coat Ag nano-particles on the surface of the modified LSCF powder. Ultimately, a LSCF-Ag composite powder uniformly coated and homogeneously distributed with $\mathrm{Ag}$ nano-particles was fabricated by the e-beam irradiation technique and the particle size of coated $\mathrm{Ag}$ nano-particles was less than $10 \mathrm{~nm}$.

A tubular single cell composed of a composite LSCF-Ag cathode, a GDC interlayer, ScSZ electrolyte and a Ni/ScSZ anode support tube was fabricated. The performance of the tubular single cell with the LSCF-Ag composite cathode was evaluated. The maximum power densities were 56.9, 113.9, and $198.1 \mathrm{~mW} / \mathrm{cm}^{2}$ where the operation temperatures of the single cell were 600,650 , and $700{ }^{\circ} \mathrm{C}$, respectively.

From the obtained results, it is anticipated that the LSCFAg cathode prepared by using e-beam irradiation can be exploited to lower the operating temperature of SOFCs.

Acknowledgments. This work was supported by a cooperation research project funded by Ministry of Education Science and Technology, Republic of Korea. This work was supported by a grant from project of research and development reserve fund of KAERI. This work was supported by a grant from the National Research Foundation of Korea (NRF) funded by the Ministry of Science, ICT \& Future Planning (No. 20110030465).

\section{References}

1. Simmer, S. P.; Bonnett, J. F.; Canfield, N. L.; Meinhardt, K. D.; Shelton, J. P.; Sprenkle, V. L.; Stevenson, J. W. J. Power Sources $2003,113,1-10$.

2. Sasaki, K.; Tamura, J.; Dokiya, M. Solid State Ionics 2001, 144, 
233-240.

3. Sasaki, K.; Tamura, J.; Hosoda, H.; Lan, T. N.; Yasumoto, K.; Dokiya, M. J. Solid State Ionics 2002, 148, 551-555.

4. Wang, L. S.; Barnett, S. A. J. Solid State Ionics 1995, 76, 103-113.

5. Uchida, H.; Yoshida, M.; Watanabe, M. J. Electrochem. Soc. 1999, 146, 1-7.

6. Uchida, H.; Arisaka, S.; Watanabe, M. J. Solid State Ionics 2000, 135, 347-351.

7. Lee, H. Y.; Cho, W. S.; Oh, S. M. Bull. Korean Chem. Soc. 1998, 19, 661-666.

8. Lim, Y. T.; Son, J. Y. Bull. Korean Chem. Soc. 2013, 34, 28222824.

9. Wang, S.; Katsuki, M.; Dokiya, M.; Hashimoto, T. Solid State Ionics 2003, 159, 71.

10. Katsuki, M.; Wang, S.; Dokiya, M.; Hashimoto,T. J. Solid State Ionics 2003, 156, 453-461.
11. Wang, S.; Kato, T.; Nagata, S.; Honda, T.; Kaneko, T.; Iwashita, N.; Dokiya, M. J. Solid State Ionics 2002, 146, 203.

12. Sakito, Y.; Hirano, A.; Imanishi, N.; Takeda, Y.; Yamamoto, O.; Liu, Y. J. Power Sources 2008, 182, 476.

13. Haanappel, V. A. C.; Rutenbeck, D.; Mai, A.; Uhlenbruck, S.; Sebold, D.; Wesemeyer, H. J. Power Sources 2004, 130, 119.

14. Chandran, S. P.; Chaudhary, M.; Pasricha, R.; Ahmad, A.; Sastry, M. Biotechnol. Prog. 2006, 22, 577-583.

15. Henglein, A. J. Phys. Chem. 1993, 97, 547-5471.

16. Woods, R. J.; Pikaev, A. K. Applied Radiation Chemistry; John Wiley \& Sons, Inc: New York, USA, 1993; p 4.

17. Wang, Z.; Xu, C.; Lou, Z.; Qiao, J.; Ren, B.; Sun, K. J. Hydrogen Energy 2013, 38, 1074.

18. Sholklapper, T. Z.; Radmilovic, V.; Jacobson, C. P.; Visco, S. J.; De Jonghe, L. C. J. Power Sources 2008, 175, 206. 